\title{
Sealants and White Spot Lesions in Orthodontics: A Review
}

\author{
Amal I Linjawi
}

\begin{abstract}
Aim: This literature review aims to update the evidence for prevention of white spot lesion (WSL) using orthodontic sealants among patients with fixed orthodontic appliances.

Background: As a major issue among orthodontists, prolonged treatment duration increases the risk of plaque development around orthodontic brackets and bands. In consequence, this can lead to heightened risk for caries development and higher possibility of WSL development around fixed orthodontic brackets.

Results: Increased prevalence of WSLs generally occurs during orthodontic treatment. This review explored various products of orthodontic sealants used to prevent WSL. Orthodontic sealants do not require patient compliance and thus will further lessen the burden among orthodontists as well as support enamel surface for a long period of time during treatment. Certain factors, however, are considered important in the efficacy of these sealants, such as antibacterial activity, color stability, resistance to acid and brush abrasion, and their effect on shear bond strength (SBS). Conclusion: The review showed that the use of orthodontic sealants in preventing WSLs during and after fixed orthodontic treatment is significantly effective. However, the bioactive glass is deemed more effective against WSL development due to its ability to immediately repair enamel surface, low cytotoxicity, and high biocompatibility. Moreover, clinical studies on bioactive glass are still needed to determine its acceptability among patients with fixed orthodontic appliance.

Clinical significance: Development of WSL around the orthodontic brackets during treatment is a difficult task among orthodontists. As such, this review explored various strategies to effectively combat WSL development for good oral health and esthetics during orthodontic treatment.

Keywords: Demineralization, Fixed orthodontics, Orthodontic sealants, Remineralizing agent, White spot lesions.

The Journal of Contemporary Dental Practice (2020): 10.5005/jp-journals-10024-2882
\end{abstract}

\section{BACKGROUND}

White spot lesion (WSL) development around the periphery of orthodontic brackets is a key concern among orthodontists, as it can bring forth difficulty in proper oral hygiene maintenance, plaque retention around the orthodontic brackets, and occurrence of enamel demineralization. ${ }^{1}$ Although orthodontic treatment can provide optimum results, the lengthy treatment process can lead to amplified accumulation of plaque around orthodontic brackets and bands. Consequently, this could lead to increased likelihood of WSL formation as well as heightened risk of caries around immobile orthodontic brackets. ${ }^{1}$ WSL is characterized by enamel demineralization or decalcification that can develop into carious cavitation when untreated, in addition to esthetic problems. ${ }^{2}$ Increment in prevalence of WSL among orthodontic patients, which are specifically present on the buccal surfaces of the enamel in the gingival areas situated near the brackets, frequently occurs after about 6-12 months of orthodontic treatment. ${ }^{1}$ Hence, reduction and prevention of demineralization can be augmented by proper WSL diagnosis and prevention, as it may compromise the patients' smile after orthodontic treatment. ${ }^{2}$

\section{Materials and Methods}

Information search for clinical and laboratory studies published between January 2000 and February 2020 was performed in search engines such as Google Scholar, PubMed, ScienceDirect, Embase, and the Cochrane Library. The following key words were used in this research: orthodontic sealants, remineralizing agent, white spot lesion, demineralization. The selection criteria used were in vivo and in vitro studies written in English language that assess WSL prevention or treatment using orthodontic sealants in the treatment duration among patients with fixed orthodontic appliances. About
Orthodontic Department, Faculty of Dentistry, King Abdulaziz University, Jeddah, Kingdom of Saudi Arabia

Corresponding Author: Amal I Linjawi, Orthodontic Department, Faculty of Dentistry, King Abdulaziz University, Jeddah, Kingdom of Saudi Arabia, Phone: +966 504155573, e-mail: ailinjawi@kau.edu.sa

How to cite this article: Linjawi Al. Sealants and White Spot Lesions in Orthodontics: A Review. J Contemp Dent Pract 2020;21(7):808-814. Source of support: Nil

Conflict of interest: None

88 articles were used for this literature review. Each study was analyzed and classified with reference to scientific evidence.

\section{Results}

To prevent development of caries in the long run, a variety of materials were recommended in WSL management which showed variable results. ${ }^{3-7}$ Clinical WSL remineralization is an extensive procedure made difficult by harsh oral cavity condition, such as variable oral cavity, $\mathrm{pH}^{8}$ and different abrasion challenges that can dilute or wash out any applied remineralizing agent., ${ }^{9,10}$

Various research explored the correlation between fixed orthodontic appliance and WSL formation. This led to innovative efforts in improving orthodontic adhesives that minimize decalcification without sacrificing its bond strength. Numerous anticaries adhesives have been investigated specifically for their effect on the bond strength of orthodontic brackets, as this is considered an added challenge in orthodontics. ${ }^{9,10}$ Sufficient bond strength is needed to endure masticatory forces and to allow the normal course of orthodontic treatment without recurrent bracket 
debonding which may lead to different orthodontic outcomes and prolonged treatment duration. ${ }^{11-13}$

Fluoride is an active remineralizing agent deemed to be an effective prophylaxis in enamel protection against WSL. It is found to be most effective when applied topically ${ }^{7,13}$ Fluoride supplement can be found as an additive product in mouthwashes, gels, toothpastes, varnishes, sealants, and elastomers., ${ }^{2,-26}$ Fluoride varnishes can result in $44.3 \%$ reduction in enamel demineralization. ${ }^{19,27,28}$ Several studies revealed the effectiveness of fluoride varnish application every 6 weeks during orthodontic treatment. ${ }^{22}$ Perrini et al. mentioned the effectiveness of periodic fluoride varnish application on patients undergoing fixed orthodontic treatment in delivering substantial defense against WSLs due to continuous fluoride release for a long duration. ${ }^{29}$ However, fluoride supplement application requires numerous visits, ${ }^{13-15}$ and compliance is hardly attained among young patients. Fluoride is also believed to inhibit bacterial metabolism, although there is no proof of such activity yet. ${ }^{13}$

Alternatively, in the field of orthodontics, many fluoridereleasing primers, adhesives, and sealants have been produced in an attempt to have a sustained release of fluoride along the whole duration of the orthodontic treatment and thus help in minimizing or preventing WSLs. ${ }^{30-33}$ However, primers are not the scope of the current review.

The current review will discuss the different sealants used in orthodontics as preventive agents against WSLs.

\section{Orthodontic Sealants}

Orthodontic practices using sealants have been extensively studied and proven in preventing WSL development and in arresting any further lesion progression without the need for irreversible tooth preparation. ${ }^{34}$ Fluoride-containing sealants are deemed essential due to high correlation between WSL and fixed orthodontic appliances. ${ }^{35}$ Those sealants were claimed to improve the bond strength and seal the etched enamel without the need for compliance among patients. ${ }^{36}$

An ideal orthodontic sealant is characterized by adequate fluoride release, color stability, adequate hardness, ${ }^{10}$ biofilm bacterial formation prevention, resistance to acid penetration, and wear abrasion resistance. Additionally, enough bond strength is also deemed necessary due to prolonged retention on the enamel during treatment. ${ }^{7,10}$ Various types of orthodontic sealants being used include filled, unfilled resin-based sealants, and resin-modified glass ionomer-based sealants. ${ }^{37}$ The current review will discuss several sealants such as Proseal, Light bond, Opalseal, DenteShield, and others that have been introduced commercially and tested experimentally.

\section{Proseal}

Proseal (Reliance Orthodontic Products, Itasca, IL 60143 USA) is a fluoride-releasing filled resin sealant. It was claimed to protect enamel surface without the need for reapplication around orthodontic brackets. ${ }^{38}$

Proseal was reported to be efficient in preventing demineralization with or without brushing and use of mouthwash compared to brushing alone. ${ }^{39}$ An in vitro study by Buren and others ${ }^{40}$ revealed a statistically significant reduction in lesion depth when Proseal was used in comparison to the control group. Others also found a $97 \%$ decline in lesion development when Proseal was used in comparison to the control group. ${ }^{40-42}$ Another in vitro study conducted in 2005 revealed significantly lower tooth demineralization when Proseal was used as enamel sealant in comparison to other types of sealants. ${ }^{36,42}$ Paschos et al. also studied the efficacy of four protective agents against enamel decalcification. ClinproXT (resin-modified glass ionomer (RMGI) cement varnish) and Proseal (composite sealant) were applied around the bracket periphery after bonding as protective agents against acid attack. Those two agents were compared to unprotected enamel surfaces that were bonded with 2 conventional bonding agents. Their results showed the efficacy of ClinproXT and Proseal in WSL prevention just immediately at the bracket periphery which significantly differed from the other two groups bonded with conventional bonding agents. However, demineralization was apparent in the adjacent areas far from the bracket periphery in all the groups. ${ }^{35}$ Premaraj and others ${ }^{10}$ evaluated the surface properties of Proseal and Opalseal and their efficacy in fluoride release. The researchers also concluded a clinically insufficient fluoride release for both Proseal and Opalseal and thus a minimal role in demineralization prevention due to their short duration of fluoride release. ${ }^{10}$ On the other hand, Proseal was found to have less Streptococcus mutans adhered to it compared to Opal Seal, which is deemed relevant in biofilm and WSL formation. ${ }^{10}$

Proseal has also been tested for its wear and abrasion resistance. In 2013, Steiner and others investigated the consequence of toothbrush abrasion as well as the acidic and thermal stresses on different sealants: Proseal, Light Bond, and Seal and Protect sealants. ${ }^{34}$ High-filled Proseal sealant was deemed more efficient in comparison to low-filled sealants. However, enamel surface deterioration in all tested materials were pronounced after a year of toothbrushing. ${ }^{34}$ This was confirmed by another study that assessed the mechanical and esthetic properties of Proseal and revealed highly significant wear resistance when compared to Opalseal. ${ }^{7}$ However, Proseal was proven to be prone to color instability and discoloration. ${ }^{7,37,42}$

Proseal was also tested for its effect on the shear bond strength (SBS) but with varied results. A study conducted by Paschos and others indicated that Proseal does not cause a negative SBS effect when it was applied alone. However, substantially higher SBS values were reported when Proseal and phosphoric acid etching were utilized. ${ }^{43}$ Lowder et al. ${ }^{44}$ reported that the SBS values of four adhesive groups, which contained Proseal, were reduced compared to a control group. However, the SBS ranged from 10.1 to $15.9 \mathrm{MPa}$ which was clinically acceptable. They also found that more than half of the adhesive remained on the tooth surface after debonding when using the sealants. ${ }^{44}$ Moreover, El Bokle and others ${ }^{45}$ reported no statistical variation in the mean SBS of orthodontic brackets when Proseal varnish was applied compared to conventional adhesive. Similarly, an in vivo study by Varlik and Demirbas showed that teeth treated with Proseal had $2.9 \%$ bond failure rate only, and a mean failure rate duration of 127 days that was not statistically different than teeth bonded with conventional composite resin alone. ${ }^{38}$ This was also confirmed by Tarvade et al. ${ }^{46}$ who reported clinically acceptable SBS brought by Proseal, despite substantially lower SBS when compared to the control group.

Studies so far showed that Proseal have adequate fluoride release but not for a long period, prevention of biofilm formation, wear resistance, resistance to acid penetration, and clinically insignificant effect on SBS. However, Proseal was found to have low color stability and need frequent reapplication because of its low fluoride release. Thus, some claimed that there were not enough 
justifiable results to indicate that Proseal has better effect than the conventional adhesives in the prevention of WSLs and thus might not be worth the time and expenses. ${ }^{41}$

\section{Light Bond Sealant}

Light Bond Filled Sealant (Reliance, Reliance Orthodontic Products, Itasca, IL, USA) is formulated with a patented fluoride-releasing monomer and contains up to $40 \%$ micro-particle size filler. ${ }^{34}$

The protection of Light Bond sealants against enamel demineralization is not well proven and studies assessing its efficacy showed varied results. ${ }^{47-50}$ Tanna et al. assessed in vitro the resistance of Light Bond sealant to enamel decalcification and compared it to self-etching primer and a control enamel with no treatment. They revealed that Light Bond sealant provided $50 \%$ more protection against enamel demineralization compared to the other two groups. However, neither the sealant nor the selfetching primer completely protected the teeth against WSL. ${ }^{48}$ Similar findings were reported for Light Bond sealant in vivo when compared to self-etching primer. ${ }^{49}$ In a study involving orthodontic sealants and daily NaF rinse, Pratt and others ${ }^{50}$ observed a substantial decline in lesion depth when either Light Bond or Proseal in conjunction with $\mathrm{NaF}$ rinse were used, compared to sealants alone. ${ }^{50}$

Enamel surface discoloration was more evident when glass ionomer-based and filled composite sealants were used..$^{37}$ This was evident in the study of Corcodel et al. who reported that Light Bond sealant, which is a composite resin-based sealant with microfillers, showed better color stability when compared to Proseal that is a composite resin-based sealant with fillers and ClinproXT that is a resin-modified glass ionomer-based sealant. ${ }^{37}$

Light Bond sealant was found to reduce the SBS. Heinig et al. found a strong correlation between this sealant application and the incidence of bracket debonding. ${ }^{47}$

Thus, it was recommended by numerous researchers to limit the application of Light Bond sealant, as it can lead to enamel discoloration and reduced SBS. ${ }^{34,37,47-50}$

\section{Opalseal}

Opalseal (OS) (Ultradent, Salt Lake City, UT) is a photo-cure surface sealant with $38 \%$ glass ionomer particles and nanofillers designed for protecting and preparing the etched enamel surface for orthodontic brackets bonding. It was commercially presented as a fluoride-releasing bonding primer with an amplified possibility of demineralization prevention in bracket-adjacent areas. ${ }^{51}$

Pennella et al. ${ }^{51}$ observed significant decline in WSL formation when Opalseal was used. Despite the 90-day retention of Opalseal layer on half of the enamel surfaces observed in their study, there was no significant difference in the overall WSL quantity between Opalseal and conventional Transbond XT, which could be attributed to potential loss of Opalseal layer over time. ${ }^{51}$ Tüfekçi and others ${ }^{52}$ also determined no substantial variation between Opalseal and control in terms of demineralization reduction via visual examination. Nonetheless, visual examination is deemed somewhat inaccurate in detecting demineralization. ${ }^{53}$ Baysal and others ${ }^{54}$ also found no substantial difference between the control and the Opalseal in terms of efficacy against WSLs. Likewise, demineralization evaluation via microcomputed tomography revealed no substantial difference between WSL rates of different adhesives and volumetric measurements, despite minimal lesion volumes recorded for Opalseal. ${ }^{55}$

A study on the mechanical and esthetic properties of both Opalseal and Proseal revealed significantly higher hardness and wear resistance values for Proseal, while Opalseal showed a better color stability. ${ }^{7}$

Tooth brushing and masticatory factors during food consumption can affect the durability of sealant and reduce the varnish layer thickness. ${ }^{56}$ Knösel and others ${ }^{56}$ suggested Opalseal reapplication after every 3.5 months, as a single application was deemed insufficient in lasting throughout the orthodontic treatment. Bartels and colleagues ${ }^{57}$ reported that Opalseal is an efficient enamel sealant against erosive attack brought by waters and soft drinks. ${ }^{57}$

A comparative study by Premaraj ${ }^{10}$ revealed significantly higher fluoride release and more adherence of $S$. mutans for Opalseal when compared to Proseal. In terms of acid penetration, both sealants significantly protected the enamel surfaces in comparison to unsealed control. ${ }^{58}$ Another study revealed no significant difference between various sealants in terms of SBS. ${ }^{59}$ As mentioned by Van Bebber and others, ${ }^{60}$ sealants' filler content has an effect on the retention of sealants on the enamel surface.

Thus, studies so far showed that Opalseal have adequate fluoride release, color stability, resistance to acid penetration, and clinically insignificant effect on SBS. However, Opalseal was found to have low wear resistance and needs frequent reapplications. It was also found to have less resistance to biofilm formation. Also, enamel surface discoloration was found more evident when glass ionomer-based and filled composite sealants such as Opalseal were used. ${ }^{37}$

\section{Ortho-coat}

Ortho-coat (Pulpdent corporation) is another fluoride-releasing sealant that can avert micro-leakage when adhered to the tooth structure as a light cure and a chemical cure adhesive. ${ }^{61}$ Given its light cure nature, immediate application and curing for 20 seconds is necessary after bracket bonding, with reapplication via etching at follow-up visits. Removal of air-inhibited layer using dry cotton pellet or alcohol after sealant placement is also required because of its chemical cure feature. ${ }^{61}$

According to Tuncer et al., ${ }^{62}$ Ortho-coat application coupled with two different self-etching primers did not significantly affect the SBS of orthodontic brackets to enamel, with no variation in adhesive remnant index. However, Abdelnaby and Al-Wakeel revealed an upsurge in the SBS and substantial microleakage decline for Ortho-coat coupled with Transbond XT, which may be due to the barrier around bracket and adhesive agents. ${ }^{61}$ Such findings do not support the use of Ortho-coat as a remineralizing sealant.

\section{SeLECT Defense}

SeLECT Defense is a unique plaque-inhibiting dental sealant, as it contains selenium that acts as an antibacterial barrier and prevents plaque buildup around orthodontic brackets. A study involving this sealant revealed no significant effect on WSL incidence on the sealant-receiving group. It can help reduce WSL prevalence when coupled with excellent oral hygiene, yet no significant effect when used solely. ${ }^{63}$ 


\section{BisCover LV}

Another light-cure material is BisCover LV, which is a low-viscosity liquid polish resin applied on enamel using brush. After application, it is left for 15 seconds to evaporate without air-drying and lightcured for 30 seconds using halogen or LED light.

A comparative study using Proseal, OrthoCoat, SeLECT Defense, and Biscover LV showed substantial enamel demineralization reduction for all materials provided in comparison to the untreated control group, with $64 \%$ decline in lesion depth for OrthoCoat, SeLECT Defense, $67 \%$ for Biscover LV, and $82 \%$ for Proseal. ${ }^{64}$ This was also supported by O'Reilly et al. ${ }^{65}$ Further findings showed that sealants cannot prevent WSL development for the entirety of treatment duration. ${ }^{65}$

\section{DenteShield}

Denteshield is another orthodontic sealant with selenium-based organic compound that inhibits bacterial growth. Amaechi et al. conducted a study, in 2018, comparing DenteShield with Proseal and Opalseal. They revealed that DenteShield is efficient as a primer and an antidemineralizing sealant during fixed orthodontic treatment without an effect on the SBS of brackets. ${ }^{66}$ However, another study suggested the importance of adequate oral hygiene in conjunction to Denteshield Defense in reducing WSL prevalence as it had no significant effect when used solely. ${ }^{63}$

\section{Beauty Ortho Bond}

Beauty Ortho bond is a light-cure orthodontic adhesive system with fast and simple application technique. It consists of a selfetching primer and a fluoride-containing paste. The paste contains surface pre-reacted glass-ionomer (S-PRG) filler. The S-PRG fillers is responsible for the fluoride release and recharge to ensure easy debonding with minimal enamel demineralization. ${ }^{67}$ Tomiyama and colleagues ${ }^{67}$ compared the effect of five orthodontic materials for the inhibition of enamel demineralization which were Beauty Ortho Bond, Beauty Ortho + Salivatect (which has the same components as the Beauty Ortho Bond but for less S-PRG filler), Kurasper F (fluoride releasing composite), Transbond XT (fluoride releasing composite), Fuji Orthos (resin-modified glass-ionomer), and Superbond Orthomite (non-fluoride releasing composite) as a control. They revealed that Beauty Ortho Bond, Beauty Ortho + Salivatect, and Fuji Ortho, which are fluoride-releasing materials, developed shallow lesions, distinct surface layers, and significantly lower mineral loss in comparison to Transbond XT and Superbond Orthomite. More studies are needed to assess the effect of Beauty Ortho Bond for adequate fluoride release, color stability, adequate hardness, biofilm formation prevention, resistance to acid penetration, wear abrasion resistance, and their effect on bracket bond strength.

\section{Clearfill Protect Bond}

Clearfil Protect Bond is an antibacterial monomer-containing adhesive. Limited studies were conducted on this sealant. Uysal and others ${ }^{68}$ investigated in vivo the protective effect of Clearfill sealant compared to Transbond control group for 30 days follow-up. Their results showed significantly lower enamel demineralization for Clearfil Protect Bond when compared to Transbond XT. ${ }^{68}$

\section{Bioglass}

Over the past few decades, Bioglass has been proposed to replace, repair, or augment parts of the skeletal system due to its similar composition to the mineral portion of bony and dental tissues. ${ }^{69,70}$ Similarly, Bioglass has been introduced as bone repairstimulating implant material. ${ }^{71}$ Bioglass has other features, such as osteoconductivity and chemical bonding, to bone via ion release to form hydroxyapatite and/or hydroxycarbonate apatite, which made it valuable as a mineralization material in dentistry. ${ }^{69-72}$ Prior in vitro studies on bioactive glass (BAG) suggested its role as a remineralizing agent of dentin surface. ${ }^{73-75}$

Bakry and others ${ }^{74}$ established adequate biocompatibility of Bioglass $45 \mathrm{~S} 5$ without significant cytotoxicity on cultured rat pulp cells when comparted to other tested material, which indicates its safety as a material for dental treatment. ${ }^{74}$ Bakry et al. also showed its durablility after subjecting it to brushing abrasion wear challenge and can penetrate within orifices of the dentinal tubules. ${ }^{9}$ A recently produced composite resins with BAG was shown to buffer the acidic oral environments with pronounced calcium ion release. It has also shown to form tooth-like hydroxyapatite crystals. Thus, it is emerging as a promising remineralizing agent to prevent WSL development. ${ }^{76,77}$ Brown et al. assessed four BAG-Bond materials with two of them containing fluoride. ${ }^{76}$ They found that all BAGBond had a significant release of calcium and phosphate and a significant change in $\mathrm{pH}$. However, no measurable release of fluoride was noticed. ${ }^{76}$

Furthermore, another research confirmed the ability of Bioglass to have acceptable SBS and to inhibit enamel demineralization via release of good number of multiple ions. ${ }^{78,79}$ Thus, Bioglass is predicted to be a novel material that might reduce or prevent WSLs during orthodontic treatment. ${ }^{72-79}$

\section{Discussion}

White spot lesions are a consequence of enamel demineralization and more frequently seen among orthodontic patients. ${ }^{80}$ It generally appears on the cervical and middle third of the labial (buccal) surfaces of the maxillary anterior, mandibular canines, and posterior segment around the periphery of orthodontic brackets that can be visible after 1 month of fixed orthodontic treatemnt. ${ }^{80-82}$ Risk factors, such as young age and poor oral hygiene prior and during treatment, were attributed in caries development during treatment. ${ }^{83-88}$

Good oral hygiene and use of antimicrobial agents are considered as effective countermeasures for WSL development. However, patient compliance is hardly attained and remains to be one of the challenges faced by orthodontists. ${ }^{83,88}$ Due to long-term effects of WSLs, many researches have delved into orthodontic sealants with antibacterial activity to curb WSL incidence among patients with fixed appliances. Majority of these orthodontic sealants contain fluoride that is deemed effective without the need for patient compliance. In addition, newer forms of orthodontic sealants had explored the possibilities of selenium in preventing WSL development. Although effective, reapplication of these sealants after several weeks is still necessary, as concentrations of fluoride or selenium limits the ability of these sealants to prevent WSL development in the long run. Aside from antibacterial activity, other retention factors, such as color stability and resistance to acid and brush abrasion, are considered in the efficacy of these sealants. Although some orthodontic sealants can act on itself, prevalence of WSL can be prevented via synergistic activity of a combination of these sealants and other oral hygiene regimens.

On the other hand, many studies on BAG suggest its role in the remineralization of dentin surface. ${ }^{9,72,73}$ Aside from its low 
cytotoxicity and high biocompatibility, Bioglass paste serves as a temporary restorative material with no esthetic problem during its application, as the interaction layer transforms from microscopic brushite crystals to a hydroxyapatite layer within 14 days without exposure to any acidic challenge. ${ }^{9,74}$ These characteristics provide a promising path for Bioglass as the future of WSL prevention. However, more clinical studies are needed to determine its acceptability among patients with fixed orthodontic appliances.

Prevention of WSL among patients with fixed orthodontic appliances continues to be a consideration among orthodontists. Many studies have focused on developing varied strategies without the need for patient compliance and cooperation, as it is hardly attained especially among younger patient population. Factors contributing to enamel demineralization, such as antibacterial activity and resistance to wear abrasion and acid challenge, have been explored to immediately curb WSL development, as it can lead to carious dentition. These strategies sought to combat WSL development can be of great help to maintain good oral health while undergoing orthodontic treatment.

\section{Conclusion}

Orthodontic sealants are deemed useful in temporary tooth protection against WSL development for the duration of orthodontic treatment. However, their efficacy against WSLs are still limited by their antimicrobial activity, color stability, and their ability to resist acidic oral $\mathrm{pH}$ and abrasions caused by brushing. Bioglass application is deemed as a more effective approach to immediately combat WSL development, given its low cytotoxicity and high biocompatibility. However, more clinical studies are required prior to its acceptability among patients undergoing treatment with fixed orthodontic appliance.

\section{Clinical Significance}

Prevention of WSL around the orthodontic brackets during treatment is a difficult task among orthodontists. As such, this review explored various strategies to effectively combat WSL development for good oral health and esthetics during orthodontic treatment.

\section{References}

1. Tüfekçi E, Dixon JS, Gunsolley JC, et al. Prevalence of white spot lesions during orthodontic treatment with fixed appliances. Angle Orthod 2011;81(2):206-210. DOI: 10.2319/051710-262.1.

2. Bishara S, Ostby A. White spot lesions: Formation, prevention, and treatment. Semin Orthod 2008;14(3):174-182. DOI: 10.1053/ j.sodo.2008.03.002.

3. Hoffman DA, Clark AE, Rody WJ,Jr, et al. A prospective randomized clinical trial into the capacity of a toothpaste containing NovaMin to prevent white spot lesions and gingivitis during orthodontic treatment. Prog Orthod 2015;16(1):25. DOI: 10.1186/s40510-015-00958.

4. Huang GJ, Roloff-Chiang B, Mills BE, et al. Effectiveness of MI paste plus and PreviDent fluoride varnish for treatment of white spot lesions: a randomized controlled trial. Am J Orthod Dentofacial Orthop 2013;143(1):31-41. DOI: 10.1016/j.ajodo.2012.09.007.

5. Llena-Puy C. MI paste plus and PreviDent fluoride varnish appear no more effective than normal home care for improving the appearance of white spot lesions. J Evid Based Dent Pract 2013;13(3):114-116. DOI: 10.1016/j.jebdp.2013.07.012.

6. Mohanty P, Padmanabhan S, Chitharanjan AB. An in vitro evaluation of remineralization potential of Novamin ${ }^{\oplus}$ on artificial enamel sub-surface lesions around orthodontic brackets using energy dispersive X-ray analysis (EDX). J Clin Diagn Res 2014;8(11):ZC88-ZC91. DOI: 10.7860/JCDR/2014/9340.5177.

7. Premaraj TS, Rohani N, Covey D, et al. An in-vitro evaluation of mechanical and esthetic properties of orthodontic sealants. Eur J Dent 2014;8(4):487-492. DOI: 10.4103/1305-7456.143630.

8. Bakry AS, Marghalani HY, Amin OA, et al. The effect of a Bioglass paste on enamel exposed to erosive challenge. J Dent 2014;42(11):14581463. DOI: 10.1016/j.jdent.2014.05.014.

9. Bakry AS, Takahashi H, Otsuki M, et al. The durability of phosphoric acid promoted Bioglass-dentin interaction layer. Dent Mater 2013;29(4):357-364. DOI: 10.1016/j.dental.2012.12.002.

10. Premaraj TS, Rohani N, Covey D, et al. In vitro evaluation of surface properties of $\mathrm{Pro} \mathrm{Seal}^{\circledR}$ and $\mathrm{Opal}^{\circledR}$ seal(TM) in preventing white spot lesions. Orthod Craniofac Res 2017;20(Suppl 1):134-138. DOI: 10.1111/ ocr.12181.

11. Fleischmann LA, Sobral MC, Santos Junior GC, et al. A comparative study of six types of orthodontic brackets with regard to bond strength. Rev Dent Press Ortodon Ortop Facial 2008;13(4):107-116. DOI: 10.1590/S1415-54192008000400013.

12. Lin CL, Huang SF, Tsai HC, et al. Finite element sub-modeling analyses of damage to enamel at the incisor enamel/adhesive interface upon de-bonding for different orthodontic bracket bases. J Biomech 2010;44(1):134-142. DOI: 10.1016/j.jbiomech.2010.08.038.

13. Øgaard B, Larsson E, Henriksson T, et al. Effects of combined application of antimicrobial and fluoride varnishes in orthodontic patients. Am J Orthod Dentofacial Orthop 2001;120(1):28-35. DOI: 10.1067/mod.2001.114644.

14. Øgaard B, Bishara SE, Duschner H. Enamel effects during bondingdebonding and treatment with fixed appliances. In: Graber TM, Eliades T, Atanasiou A. Risk Management in Orthodontics: Experts' Guide to Malpractice. Chicago, USA: Quintessense Publishing Co; 2004.

15. Al-Mulla A, Karlsson L, Kharsa S, et al. Combination of highfluoride toothpaste and no post-brushing water rinsing on enamel demineralization using an in-situ caries model with orthodontic bands. Acta Odontol Scand 2010;68(6):323-328. DOI: 10.3109/00016357.2010.512863.

16. Bergstrand $\mathrm{F}$, Twetman S. A review on prevention and treatment of post-orthodontic white spot lesions - evidence-based methods and emerging technologies. Open Dent J 2011;5(1):158-162. DOI: 10.2174/1874210601105010158.

17. Marinho VC. Cochrane reviews of randomized trials of fluoride therapies for preventing dental caries. Eur Arch Paediatr Dent 2009;10(3):183-191. DOI: 10.1007/BF03262681.

18. Walsh T, Worthington HV, Glenny AM, et al. Fluoride toothpastes of different concentrations for preventing dental caries in children and adolescents. Cochrane Database Syst Rev 2010;20(1):CD007868. DOI: 10.1002/14651858.CD007868.pub2.

19. Zabokova-Bilbilova E, Popovska L, Kapusevska B, et al. White spot lesions: prevention and management during the orthodontic treatment. Pril (Makedon Akad Nauk Umet Odd Med Nauki) 2014;35(2):161-168. DOI: 10.2478/prilozi-2014-0021.

20. Richter AE, Arruda AO, Peters MC, et al. Incidence of caries lesions among patients treated with comprehensive orthodontics. Am J Orthod Dentofacial Orthop 2011;139(5):657-664. DOI: 10.1016/ j.ajodo.2009.06.037.

21. Bahoum A, Bahije L, Zaoui F. Enamel demineralization in orthodontics. Systematic use of fluoride in prevention and treatment. Schweiz Monatsschr Zahnmed 2012;122(10):937-947.

22. Benson PE, Parkin N, Dyer F, et al. Fluorides for the prevention of early tooth decay (demineralised white lesions) during fixed brace treatment. Cochrane Database Syst Rev 2013;12(12):CD003809. DOI: 10.1002/14651858.CD003809.pub3.

23. Benson PE, Parkin N, Millett DT, et al. Fluorides for the prevention of white spots on teeth during fixed brace treatment. Cochrane Database Syst Rev 2004(3):CD003809. DOI: 10.1002/14651858. CD003809.pub2. 
24. Srivastava K, Tikku T, Khanna R, et al. Risk factors and management of white spot lesions in orthodontics. J Orthod Sci 2013;2(2):43-49. DOI: $10.4103 / 2278-0203.115081$.

25. Sudjalim TR, Woods MG, Manton DJ. Prevention of white spot lesions in orthodontic practice: a contemporary review. Aust Dent J 2006;51(4):284-289. DOI: 10.1111/j.1834-7819.2006.tb00445.xquiz 347.

26. Benson PE, Pender N, Higham SM. Quantifying enamel demineralization from teeth with orthodontic brackets-a comparison of two methods. Part 2: validity. Eur J Orthod 2003;25(2):159-165. DOI: 10.1093/ejo/25.2.159.

27. Behnan SM, Arruda AO, González-Cabezas C, et al. In-vitro evaluation of various treatments to prevent demineralization next to orthodontic brackets. Am J Orthod Dentofacial Orthop 2010;138(6):712.e1-7. DOI: 10.1016/j.ajodo.2010.05.014discussion-3.

28. Demito CF, Vivaldi-Rodrigues $G$, Ramos AL, et al. The efficacy of a fluoride varnish in reducing enamel demineralization adjacent to orthodontic brackets: An in vitro study. Orthod Craniofac Res 2004;7(4):205-210. DOI: 10.1111/j.1601-6343.2004.00305.x.

29. Perrini $F$, Lombardo L, Arreghini $A$, et al. Caries prevention during orthodontic treatment: In-vivo assessment of high-fluoride varnish to prevent white spot lesions. Am J Orthod Dentofacial Orthop 2016;149(2):238-243. DOI: 10.1016/j.ajodo.2015.07.039.

30. Bishara SE, Ajlouni R, Laffoon JF, et al. Effect of a fluoride-releasing self-etch acidic primer on the shear bond strength of orthodontic brackets. Angle Orthod 2002;72(3):199-202. DOI: 10.1043/00033219(2002)0722.0.CO;2.

31. Bishara SE, Soliman M, Laffoon J, et al. Effect of antimicrobial monomer-containing adhesive on shear bond strength of orthodontic brackets. Angle Orthod 2005;75(3):397-399. DOI: 10.1043/0003-3219(2005)75[397:EOAMAO]2.0.CO;2.

32. Bishara SE, Soliman M, Laffoon JF, et al. Shear bond strength of a new high fluoride release glass ionomer adhesive. Angle Orthod 2008;78(1):125-128. DOI: 10.2319/100405-347.1.

33. Soliman MM, Bishara SE, Wefel J, et al. Fluoride release rate from an orthodontic sealant and its clinical implications. Angle Orthod 2006;76(2):282-288. DOI: 10.1043/0003-3219(2006)076[0282:FRRFA O]2.0.CO;2.

34. Korbmacher-Steiner HM, Schilling AF, Huck LG, et al. Laboratory evaluation of toothbrush/toothpaste abrasion resistance after smooth enamel surface sealing. Clin Oral Investig 2013;17(3):765-774. DOI: 10.1007/s00784-012-0771-8.

35. Paschos E, Geiger FJ, Malyk Y, et al. Efficacy of four preventive measures against enamel demineralization at the bracket peripherycomparison of microhardness and confocal laser microscopy analysis. Clin Oral Investig 2016;20(6):1355-1366. DOI: 10.1007/s00784-0151624-z.

36. Hu W, Featherstone JD. Prevention of enamel demineralization: An in-vitro study using light-cured filled sealant. Am J Orthod Dentofacial Orthop 2005;128(5):592-600. DOI: 10.1016/j.ajodo.2004.07.046quiz 70.

37. Corcodel N, Hassel AJ, Sen S, et al. Effects of staining and polishing on different types of enamel surface sealants. J Esthet Restor Dent 2018;30(6):580-586. DOI: 10.1111/jerd.12423.

38. Varlik SK, Demirbas E. Effect of light-cured filled sealant on the bond failure rate of orthodontic brackets in vivo. Am J Orthod Dentofacial Orthop 2009;135(2):144.e1-4. DOI: 10.1016/j.ajodo.2008.05.013discus sion-5.

39. Pithon MM, Santos MJ, Souza CA, et al. Effectiveness of fluoride sealant in the prevention of carious lesions around orthodontic brackets: An OCT evaluation. Dental Press J Orthod 2015;20(6):37-42. DOI: 10.1590/2177-6709.20.6.037-042.oar.

40. Buren JL, Staley RN, Wefel J, et al. Inhibition of enamel demineralization by an enamel sealant, Pro Seal: an in-vitro study. Am J Orthod Dentofacial Orthop 2008;133(4 Suppl):S88-S94. DOI: 10.1016 /j.ajodo.2007.01.025.

41. Leizer C, Weinstein M, Borislow AJ, et al. Efficacy of a filled-resin sealant in preventing decalcification during orthodontic treatment.
Am J Orthod Dentofacial Orthop 2010;137(6):796-800. DOI: 10.1016/j. ajodo.2008.11.025.

42. Coordes SL, Jost-Brinkmann PG, Präger TM, et al. A comparison of different sealants preventing demineralization around brackets. J Orofac Orthop 2018;79(1):49-56. DOI: 10.1007/s00056-017-0116-y.

43. Paschos E, Okuka S, Ilie N, et al. Investigation of shear-peel bond strength of orthodontic brackets on enamel after using Pro seal. J Orofac Orthop 2006;67(3):196-206. DOI: 10.1007/s00056-006-0541-9.

44. Lowder PD, Foley T, Banting DW. Bond strength of 4 orthodontic adhesives used with a caries-protective resin sealant. Am J Orthod Dentofacial Orthop 2008;134(2):291-295. DOI: 10.1016/ j.ajodo.2008.03.002.

45. El Bokle D, Munir H. An in vitro study of the effect of Pro Seal varnish on the shear bond strength of orthodontic brackets. World J Orthod 2008;9(2):141-146.

46. Tarvade SM, Deshmukh AA, Daokar SG. Evaluation of bond strength: an in vitro study using Pro Seal. J Int Oral Health 2014;6(4):1-3.

47. Heinig N, Hartmann A. Efficacy of a sealant: Study on the efficacy of a sealant (light bond) in preventing decalcification during multibracket therapy. J Orofac Orthop 2008;69(3):154-167. DOI: 10.1007/s00056008-0741-6.

48. Tanna N, Kao E, Gladwin M, et al. Effects of sealant and self-etching primer on enamel decalcification. Part I: an in-vitro study. Am J Orthod Dentofacial Orthop 2009;135(2):199-205. DOI: 10.1016/ j.ajodo.2008.09.003.

49. Ghiz MA, Ngan P, Kao E, et al. Effects of sealant and self-etching primer on enamel decalcification. Part II: an in-vivo study. Am J Orthod Dentofacial Orthop 2009;135(2):206-213. DOI: 10.1016/ j.ajodo.2007.02.060.

50. Pratt KC, Hicks J, English JD, et al. Fluoride-releasing orthodontic adhesives and topical fluoride effect on enamel caries formation: an in vitro study. Am J Dent 2010;23(3):179-184.

51. Pennella $D$. The effects of a fluoride releasing orthodontics primer on demineralization around brackets: An in-vivo study. Richmond, Virginia: Virginia Commonwealth University; 2011.

52. Tüfekçi E, Pennella DR, Mitchell JC, et al. Efficacy of a fluoridereleasing orthodontic primer in reducing demineralization around brackets: an in-vivo study. Am J Orthod Dentofacial Orthop 2014 Aug;146(2):207-214. DOI: 10.1016/j.ajodo.2014.05.016.

53. Boersma JG, van der Veen MH, Lagerweij MD, et al. Caries prevalence measured with QLF after treatment with fixed orthodontic appliances: Influencing factors. Caries Res 2005;39(1):41-47. DOI: 10.1159/000081655.

54. Baysal A, Yasa A, Sogut O, et al. Effects of different orthodontic primers on enamel demineralization around orthodontic brackets. J Orofac Orthop 2015;76(5):421-430. DOI: 10.1007/s00056-015-0304-6.

55. Oz AZ, Oz AA, Yazıcıoglu S. In vivo effect of antibacterial and fluoride-releasing adhesives on enamel demineralization around brackets: a micro-CT study. Angle Orthod 2017;87(6):841-846. DOI: 10.2319/060217-371.1.

56. Knösel M, Ellenberger D, Göldner $Y$, et al. In-vivo durability of a fluoride-releasing sealant (Opalseal) for protection against whitespot lesion formation in orthodontic patients. Head Face Med 2015;11(1):11. DOI: 10.1186/s13005-015-0069-6.

57. Bartels AA, Evans CA, Viana G, et al. Demineralization of resin-sealed enamel by soft drinks in a clinically relevant $\mathrm{pH}$ cycling model. Am J Dent 2016;29(2):115-119.

58. Pascotto RC, Navarro MF, Capelozza Filho L, et al. In vivo effect of a resin-modified glass ionomer cement on enamel demineralization around orthodontic brackets. Am J Orthod Dentofacial Orthop 2004;125(1):36-41. DOI: 10.1016/s0889-5406(03)00571-7.

59. Seeliger JH, Botzenhart UU, Gedrange T, et al. Enamel shear bond strength of different primers combined with an orthodontic adhesive paste. Biomed Tech (Berl) 2017;62(4):415-420. DOI: 10.1515/bmt-20160241.

60. Van Bebber L, Campbell PM, Honeyman AL, et al. Does the amount of filler content in sealants used to prevent decalcification on smooth 
enamel surfaces really matter? Angle Orthod 2011;81(1):134-140. DOI: 10.2319/040910-201.1.

61. Abdelnaby $\mathrm{YL}, \mathrm{Al}-$ Wakeel EE. Influence of modifying the resin coat application protocol on bond strength and microleakage of metal orthodontic brackets. Angle Orthod 2010;80(2):378-384. DOI: 10.2319/042109-223.1.

62. Tuncer C, Tuncer BB, Ulusoy C. Effect of fluoride-releasing light-cured resin on shear bond strength of orthodontic brackets. Am J Orthod Dentofacial Orthop 2009;135(1):14.e1-6. DOI: 10.1016/j.ajodo.2008.0 9.016discussion-5.

63. Hammad SM, Knösel M. Efficacy of a new sealant to prevent white spot lesions during fixed orthodontic treatment: A 12-month, single-center, randomized controlled clinical trial. J Orofac Orthop 2016;;77(6):439-445. DOI: 10.1007/s00056-016-0052-2.

64. Clark TJ, The efficacy of ProSeal ${ }^{\mathrm{TM}}$, SeLECT Defense ${ }^{\mathrm{TM}}$, OrthoCoat ${ }^{\mathrm{TM}}$, and Biscover $\mathrm{LV}^{\mathrm{TM}}$ resin sealants on the prevention of enamel demineralization and white spot lesion formation: University of lowa; 2010.

65. O'Reilly MT, Viñas JDJ, Hatch JP. Effectiveness of a sealant compared with no sealant in preventing enamel demineralization in patients with fixed orthodontic appliances: a prospective clinical trial. Am J Orthod Dentofacial Orthop 2013;143(6):837-844. DOI: 10.1016/ j.ajodo.2013.01.021.

66. Amaechi B, Najibfard K, Chedjieu I, et al. Do products preventing demineralization around orthodontic brackets affect adhesive bond strength? Open Dent J 2018;12(1):1029-1035. DOI: 10.2174/1874210601812011029.

67. Tomiyama K, Mukai Y, Teranaka T. Acid resistance induced by a new orthodontic bonding system in vitro. Dent Mater J 2008;27(4): 590-597. DOI: 10.4012/dmj.27.590.

68. Uysal T, Amasyali M, Ozcan S, et al. Effect of antibacterial monomercontaining adhesive on enamel demineralization around orthodontic brackets: an in-vivo study. Am J Orthod Dentofacial Orthop 2011;139(5):650-656. DOI: 10.1016/j.ajodo.2009.06.038.

69. Kurkjian C. Mechanical properties of phosphate glasses. J Non Cryst Solids 2000. s263-s264. DOI: 10.1016/S0022-3093(99)00637-7.

70. Santos Cardoso O, Coelho Ferreira M, Moreno Carvalho E, et al. Effect of root repair materials and bioactive glasses on microhardness of dentin. Iran Endod J 2018;13(3):337-341. DOI: 10.22037/iej.v13i3.20565.

71. Nganga S, Zhang D, Moritz N, et al. Multi-layer porous fiber-reinforced composites for implants: in vitro calcium phosphate formation in the presence of bioactive glass. Dent Mater 2012;28(11):1134-1145. DOI: 10.1016/j.dental.2012.08.005.

72. Vollenweider M, Brunner TJ, Knecht S, et al. Remineralization of human dentin using ultrafine bioactive glass particles. Acta Biomater 2007;3(6):936-943. DOI: 10.1016/j.actbio.2007.04.003.

73. Hoppe A, Güldal NS, Boccaccini AR. A review of the biological response to ionic dissolution products from bioactive glasses and glass-ceramics. Biomaterials 2011;32(11):2757-2774. DOI: 10.1016/ j.biomaterials.2011.01.004.
74. Bakry AS, Tamura Y, Otsuki M, et al. Cytotoxicity of 4555 bioglass paste used for dentine hypersensitivity treatment. J Dent 2011;39(9): 599-603. DOI: 10.1016/j.jdent.2011.06.003.

75. Bakry AS, Takahashi $\mathrm{H}$, Otsuki M, et al. CO2 laser improves $45 \mathrm{~S} 5$ bioglass interaction with dentin. J Dent Res 2011;90(2):246-250. DOI: 10.1177/0022034510387793.

76. Brown ML, Davis HB, Tufekci E, et al. Ion release from a novel orthodontic resin bonding agent for the reduction and/or prevention of white spot lesions. An in vitro study Angle Orthod 2011;81(6): 1014-1020. DOI: 10.2319/120710-708.1.

77. Manfred L, Covell DA, Crowe JJ, et al. A novel biomimetic orthodontic bonding agent helps prevent white spot lesions adjacent to brackets. Angle Orthod 2013;83(1):97-103. DOI: 10.2319/110811-689.1.

78. Bakry AS, Abbassy MA, Alharkan HF, et al. A novel fluoride containing bioactive glass paste is capable of re-Mineralizing early caries lesions. Materials (Basel) 2018;11(9):1636. DOI: 10.3390/ma11091636.

79. Bakhsh TA, Bakry AS, Mandurah MM, et al. Novel evaluation and treatment techniques for white spot lesions. An in vitro study. Orthod Craniofac Res 2017;20(3):170-176. DOI: 10.1111/ocr.12193.

80. Julien KC, Buschang PH, Campbell PM. Prevalence of white spot lesion formation during orthodontic treatment. Angle Orthod 2013;83(4):641-647. DOI: 10.2319/071712-584.1.

81. Khalaf K. Factors affecting the formation, severity and location of white spot lesions during orthodontic treatment with fixed appliances. J Oral Maxillofac Res 2014;5(1):e4. DOI: 10.5037/ jomr.2014.5104.

82. Lucchese A, Gherlone E. Prevalence of white-spot lesions before and during orthodontic treatment with fixed appliances. Eur J Orthod 2013;35(5):664-668. DOI: 10.1093/ejo/cjs070.

83. Almosa NA, Lundgren T, Aldrees AM, et al. Diagnosing the severity of buccal caries lesions in governmental and private orthodontic patients at debonding, using the ICDAS-II and the DIAGNOdent pen. Angle Orthod 2014;84(3):430-436. DOI: 10.2319/051313-371.1.

84. Chapman JA, Roberts WE, Eckert GJ, et al. Risk factors for incidence and severity of white spot lesions during treatment with fixed orthodontic appliances. Am J Orthod Dentofacial Orthop 2010;138(2):188-194. DOI: 10.1016/j.ajodo.2008.10.019.

85. Heymann GC, Grauer D. A contemporary review of white spot lesions in orthodontics. J Esthet Restor Dent 2013;25(2):85-95. DOI: 10.1111/ jerd.12013.

86. Miller MJ, Bernstein S, Colaiacovo SL, et al. Demineralized white spot lesions: an unmet challenge for orthodontists. Semin Orthod 2016;22(3):193-204. DOI: 10.1053/j.sodo.2016.05.006.

87. Sangamesh B, Kallury A. latrogenic effects of orthodontic treatmentreview on white spot lesions. Int J Sci Eng Res 2011;2(5):2-16.

88. Sundararaj D, Venkatachalapathy S, Tandon A, et al. Critical evaluation of incidence and prevalence of white spot lesions during fixed orthodontic appliance treatment: a meta-analysis. J Int Soc Prev Community Dent 2015;5(6):433-439. DOI: 10.4103/2231-0762. 167719. 